\title{
Dilemmas of Representation in Contemporary Environmental Anthropology: Documenting Dynamite Fishing in Southeastern Tanzania
}

\author{
Justin Raycraft ${ }^{1 *}$ \\ ${ }^{1}$ Department of Anthropology, McGill University, Montreal, Canada. \\ *justin.raycraft@mail.mcgill.ca
}

\begin{abstract}
This paper draws from an ethnographic vignette of dynamite fishing in southeastern Tanzania. I consider the utility of participant observation as a method for examining ecologically destructive practices, especially in contexts where such activities are illegal or prohibited by conservation regulations. I raise self-reflexive critiques, internal to my home discipline of anthropology, and discuss the methodological, ethical, and analytical challenges of attempting to document cases of dynamite fishing and other related phenomena of pressing environmental concern. Ultimately, I maintain that participant observation remains a valuable tool for documenting and explaining environmentally destructive activities.
\end{abstract}

Received September 21, 2017

OPEN ठACCESS

Accepted June 19, 2018

DOI 10.14237/ebl.9.2.2018.1115

Keywords Participant Observation, Ethnography, Destructive fishing practices, Illegal activities, Moral terrains, Interpretive anthropology

Copyright (c) 2018 by the author(s); licensee Society of Ethnobiology. This is an open-access article distributed under the terms of the Creative Commons Attribution-NonCommercial 4.0 International Public License (https://creativecommons.org/licenses/by-nc/4.0), which permits non-commercial use, distribution, and reproduction in any medium, provided the original author and source are credited.

\section{Introduction}

While conducting ethnographic fieldwork in a coastal Tanzanian village in 2014 and 2015, I spent many mornings walking along the shoreline between Mnazi Bay and the Ruvuma River, which marks the southern border with Mozambique. People often curiously asked me in KiSwahili, "Je, unafanya nini leo asububi?" ("What are you doing this morning?"), to which I would always reply with a smile, "Natembea tembea kwa mazoezi" ("I'm just walking around for exercise"). During these strolls, I often paused to chat with local fishers as they prepared to depart for the day in their dug-out canoes. On one particular morning, I stopped to speak with a group of young men, who were searching for octopus in the shallow tide pools that formed during low tides. As we began talking, we were interrupted by a loud boom from the ocean, and I looked up to see a huge splash adjacent to a small boat about 200 feet from the beach. At first, I was confused, thinking that a whale had breached directly next to the boat. As I continued to watch, however, one of the two young men in the boat stood upright and casually tossed a stick of dynamite into the water next to them. The surface once again erupted like a small volcano. "Wanatumia baruti," whispered one of the young fishers next to me: "They are using bombs."

My observations of dynamite fishing in the Mnazi Bay-Ruvuma Estuary Marine Park in the Mtwara region of Tanzania do not constitute a unique ethnographic experience. Christine Walley (2004) has previously described hearing these thunderous booms with unnerving regularity in the marine areas around Mafia Island, Tanzania's first marine park. The unmistakable sound of dynamite fishing has historically been so frequent in coastal Tanzania that it has even been referred to as the "wimbo wa taifa" (the song of the nation") in some public discourses (Kalangahe and Slade 2014:3). The question of why dynamite fishing persists in southeastern Tanzania, inside the boundaries of a multiple-use marine protected area (MPA), is deeply complex. It is a question that I will loosely address in the pages that follow; however, this is not the primary aim of this paper. Instead, I use this ethnographic vignette as a reflexive exercise for thinking critically about the role of participant observation in contemporary environmental anthropology. I consider its utility as a method 
for examining ecologically destructive practices, especially in contexts where such activities are illegal, or prohibited by conservation regulations.

I situate my own vision of a Geertzian (1973) model of environmental anthropology within the broader "umbrella" of ethnobiological scholarship (Wolverton 2013:21). While ethnobiology addresses, in a general sense, the relationships between people and their environments across space and time, Wyndham et al. (2011) also envision the field as a "creative place," where diverse scholars can intellectually congregate to discuss issues of significant social and ecological concern (Wyndham et al. 2011:111; see also Hunn 2014). In a contemporary setting, Ethnobiology 5 has become a forum for scholarly debate, criticism, and creativity (Nabhan et al. 2011). This interdisciplinary-turn has been shaped by an awareness of the fact that human-environment relations are complex and dynamic and require a "spectrum of approaches" to garner well-rounded understandings of social and ecological phenomena (Gavin et al. 2015:140; Saslis-Lagoudakis and Clarke 2013). Research in ethnobiology must also continue to address wide scholarly audiences to ensure that its relevance for addressing global environmental concerns is not overlooked (Wolverton 2013).

In this paper, I direct my commentary towards anthropologists, archaeologists, geographers, political ecologists, philosophers, and conservation biologists alike, a readership united by the cross-disciplinary "bridge" of ethnobiology (Nabhan 2009:3). However, I focus in particular on the ethnographic endeavour. I revisit theoretical critiques, internal to my home discipline of anthropology, to consider the place of participant observation in contemporary ethnobiological scholarship. I discuss the methodological, ethical, and analytical challenges of attempting to document cases of dynamite fishing and other related phenomena of pressing environmental concern. In particular, I express apprehension about the potential for ethnographers to contribute to the formation and maintenance of environmental narratives. I am deeply interested in demarcating space for participant observation as a concrete method in "conservation social science” (Bennett et al. 2017:93)1. However, I remain critical of the extent to which ethnographers can become implicated in the production of what James Clifford (1986) refers to in Writing Culture as "partial truths" (Clifford 1986:1, 7). While the majority of this paper is reflexive in scope, I ultimately contend in my concluding section that there is value in taking an ethnographic approach to documenting dynamite fishing and other related phenomena. Accurately and thoughtfully representing ecologically destructive practices is a challenging task, but can be beneficial if ethnographers are able to understand the webs of meaning in which their subjects are “suspended" (Geertz 1973:5).

\section{Ethnography and Ethnobiology}

Wyndham (2009) discusses the benefits of taking an ethnographic approach in the field of ethnobiology, highlighting the ways that ethnography can invoke the "subtle ecologies of everyday experience," or the inter -relational spheres and "lines of interaction" that exist between humans, landscapes, and other forms of life (Wyndham 2009:272). Certainly, long-term participant observation of everyday life offers a unique form of scholarly insight. Malinowski's (1922) famous approach to moving "off the verandah" and into the village is fundamental to the discipline of anthropology. As Malinowski (1922) showed, doing fieldwork in situ is an essential step in attempting "to grasp the native's point of view, his relation to life, to realize his vision of his world" (Malinowski 1922:25). Within the field of ethnobiology, participant observation has many methodological advantages. It enables researchers to directly observe what people do, rather than what they say they do. Furthermore, gathered data is organic and intertwined with everyday activities and not shaped by artificial methodological constructs. Put simply, participant observation can be an essential tool for any field researcher who seeks to understand exactly what is going on in a given setting.

Unlike subtle ecologies, however, dynamite fishing is acute and visibly jarring, and consequently demands a different form of ethnographic engagement. Participant observation in the context of dynamite fishing can be a risky endeavour both physically and politically. Even the boldest of ethnographers may be forced to forgo Favret-Saada's (2012:437) notion of an embodied form of participation observation that is "outside" of representation and "inside" of experience While off the verandah, ethnographers may have to settle for on the beach, rather than in the boat with stick of dynamite in hand. In such cases, an interpretive approach is essential.

\section{Entering the Muddy Waters of Interpretation}

As we turn our attentions towards ecologically destructive practices, we must remain cognizant of the 
politics surrounding our contributions to discourses of environmental degradation; the further we stray into applied environmental arenas, the greater the gravity of our attempts to grapple with the "crisis of representation" that has troubled ethnographers since the interpretive turn (Marcus and Fischer 1986:7). If we are to also situate contemporary environmental anthropology in relation to the post-structural turn in political ecology, we must also attend to the ways in which nature is socially and politically produced (Escobar 1999; Latour 2004). Narrative representations of the environment can contribute to the reification of new nature/society hybrids, processes which can benefit select few, at the expense of many (Fairhead and Leach 1995; Raffles 1999). Narratives are inherently political, and as such, we can never overlook the relationships between representation and power.

In many ways, this paper raises more questions than answers. My ethnographic experiences have led me to reconsider my own positionality in attempting to discuss these topics with some semblance of authority. One of my recurrent concerns is how do we, as ethnographers, negotiate ambiguity? As Blaikie (1989) points out, attempts to elucidate the drivers of social and environmental change are often shrouded in uncertainty. As ethnographers with refined observational skillsets, we are often highly attuned to the visible dimensions of social life. But which components of our field sites are we truly seeing? Where are our blind spots located? Literature in political ecology reminds us that the observable social dimensions of micro-localities are embedded within wider multi-scalar and multi-temporal political and economic arenas, which frame individual subjectivities and behaviors, and ultimately, the trajectories of social and environmental change (see for example Boelens et al. 2016).

Often our interlocutors are unwilling to openly discuss their engagements in illegal or prohibited activities, out of fear of facing repercussions for their transgressions. In such cases, the narrative accounts that we can elicit from respondents via interviews and focus group discussions are less revealing than our own observations of their behaviours. But such forms of observation often demand a degree of discreteness on behalf of the ethnographer. What are the ethical terrains of covert observational tactics?

Sometimes, we are simply not able to gain access to the social worlds of illegal activities. In such cases, we must make our interpretations from a safe distance, based only on what we can observe. But there is danger in venturing into the muddy waters of interpretation. Without insights into the true intentionality behind peoples' social actions, we as ethnographers run the risk of projecting our own schemata and conceptual frameworks onto the social phenomena that we observe. If we carefully consider Geertz's (1973) and Ryle's (1971) notion of "thick description," we realize that ethnography is not simply about describing detailed social scenes, but attempting to systematically explicate the layers of meaning that underlie the intentionality behind social action (see Geertz 1973:6-7). Without insights into the ways in which people make sense of their surroundings and lived environments, we may actively cast shadows over constituent parts of the whole picture. After all, even the most beautifully crafted ethnographies, imbued with seamlessly articulated logical reasoning, can quite simply be wrong ${ }^{2}$.

How do we as ethnographers decide which narratives are afforded authority, and in such cases of mutual exclusivity, which ones are marginalized? Narratives often function to make complex problems seem more manageable (Fairhead and Leach 1995). However, despite our best attempts to create order from disorder, variability and unpredictability often reign supreme. The reality, of course, is that in most cases of social and environmental change, we are dealing with complexity that supersedes the comprehensiveness of singularized narratives (Blaikie 1989). An attempt to unpack the drivers of dynamite fishing in coastal Tanzania, for example, demands attention to the multiplicity of narratives at play, some of which exist in harmonious polyphonies, and others that are set in direct conflict with each other (see Katikiro and Mahenge 2016). As ethnographers who must operate under perpetual conditions of uncertainty and ambiguity, we must make conscious decisions about which stories we choose to legitimize through our scholarly writing.

\section{Morality and Positionality}

The complex moral conundrums that arise while doing ethnography are certainly familiar across ethnobiological fields. While ethnobiology is multidisciplinary and diverse, one of its unifying tenets is its emphasis on ethics (Gilmore and Eshbaugh 2011; Hardison and Bannister 2011). It is a field that demands reflexive attention to how various agents are involved in acquiring and mobilizing environmental 
knowledge (Hunn 2014). If there exists an "ethnobiological perspective," it is one that is thoughtful and situated (Wolverton et al. 2014:125). As scholarship in environmental justice demonstrates, moral terrains (webs of value associated with place) are layered and inter-relational (see Figueroa and Waitt 2008, 2010). These sets of values exist relative to the approaches of local communities, scientific disciplines, and individual researchers (see Wolverton et al. 2016).

Such considerations bring up significant questions about the ways in which ethnographers should position themselves in discussions about ecologically destructive practices. Certainly, we must retain our ethical responsibilities to protect the interests of the human subjects with whom we work. This is particularly important in contexts where people are engaging in illegal activities that could subject them to direct punishments from governing authorities. This is further complicated by the fact that the stories that subjects share with ethnographers may diverge tremendously from the public accounts forwarded by conservationists and state officials. In the case of my fieldwork, villagers told stories of environmental injustice and livelihood insecurity (see also Kamat 2014). The marine park's top-down governance structure and restrictive conservation regulations engendered widespread experiences of socioeconomic vulnerability and political marginalization. Given the ethical responsibilities that I, as an anthropologist, have to my subjects, should this not feature prominently into the narrative account that I produce? As Hunn (2014:149) reminds us, long-term participant observation with communities often instills an "intense emotional engagement" with our subjects, and a desire to "deflect those social, economic, and political forces that would undermine the foundations of their lives and livelihoods".

In contexts where local communities face significant political marginalization and must bear the costs associated with environment change, the importance of integrating the moral terrains of communities into research is paramount (Gilmore and Young 2012). Engagement with these sets of values can open "moral gateways" that pave the way for social and environmental change that is beneficial for local communities (Waitt et al. 2007:261). Even so, collaboration is never simple. Such an approach demands "rigor and self-reflexivity" given its potential to privilege the views of some people, and ignore those of others (Gilmore and Young 2012:24). Such processes can serve to replicate pre-existing inequalities or even create new divisions within and across communities.

And what about the other subjects who inhabit the world? If I am, for a moment, to entertain Viveiros de Castro's (1998) multinaturalist notion that the world comprises a diversity of persons, both human and non-human, who wield a universal capacity for subjective apprehension, do I not have a duty to consider the impacts of dynamite fishing on affected wildlife? As an increasing number of scholars (see for example Bubandt and Tsing 2018; Gan et al. 2018; Ghosh 2016; Haraway 2016; Kohn 2013; Latour 2004; Tsing 2015) turn their attentions towards the entanglements of life on earth in the current Anthropocene, do we not have a wider moral imperative to consider the destructive impacts of these activities on other nonhuman beings?

What about my own personal dispositions, not as an anthropologist, but as an individual? I wield my own moral compass, my own sets of interests, and of course, my own concerns. I am, above all else, partial in my stances on most matters. Hunn (2014:149), for example, describes how his own inclinations as "an avid birder" came to shape his relationships with his subjects while living in the field. As a passionate scuba diver, I feel a very strong visceral reaction to the sight of someone tossing a stick of dynamite into a coral reef ecosystem. I cannot help but think about the potentially irreparable damage such behaviours can have on coral substrates. I imagine what the blastdamaged reefs look like beneath the surface of the ocean. As an individual and as a diver, I consider dynamite fishing to be devastating.

\section{Difficulties in Representing the Drivers of Dynamite Fishing}

In some ways, the narrative is simple, and in other ways, it is complex. I can clearly situate myself on the side of the moral fence that opposes dynamite fishing. In relation to this basic ethical stance, I could carve out a research regime aimed at unpacking the drivers of dynamite fishing, so as to contribute to attempts to stop it. But even this is an immensely complicated pursuit. Dynamite fishing, after all, is not a homogenous process. It occurs in several different forms throughout coastal Tanzania. In northern Tanzania, dynamite fishers are often from "influential" and politically well-connected families, enabling them to avoid significant repercussions if their boats are 
intercepted by authorities (Wells 2009:22). In the Kilwa district, dynamite fishers are often financed by powerful elites who provide funding for boats, fridges, and dynamite (Guard and Masaiganah 1997). This model involves "ice boats," which are used to transport dynamite catches back to Dar es Salaam via high speed motorboats, equipped with insulated ice coolers (Guard and Masaiganah 1997:759). Walley (2004:55) describes a similar trend near Mafia Island. In the Mtwara region of southeastern Tanzania, the model can be quite different. There, young dynamite fishers often operate in pairs, out of dug-out canoes (Darwall and Guard 2000) ${ }^{3}$. In general, these young men are not particularly invested in fisheries for livelihood and likely view dynamite fishing as a means of securing a better life for themselves and their families. After all, dynamite can be purchased quite cheaply "from known dealers," who acquire it from roadside construction projects or quarries (see Guard and Masaiganah 1997:761). Compared to other fishing methods, dynamite fishing can result in significantly larger catches. Thus, it offers an immediate opportunity to generate significant profits with little start-up capital. These three models of dynamite fishing differ in terms of the underlying localities of power that drive the practice. The former two are driven by wellconnected elites, the latter, by marginalized people living on the political periphery of the state.

Even these brief descriptions constitute gross oversimplifications. In attempting to document acute cases of dynamite fishing, important questions arise as to the extent to which we should emphasize agency or structural constraints in our interpretations and explanations of causality. In reflecting on my time spent living in a coastal village in rural Mtwara, I recall a conversation I had with an individual one evening, as we sat beneath a neem tree, sipping our cups of chai. Juma ${ }^{4}$ was born in the commercial capital of Dar es Salaam, but had been living in Mtwara for some time, given its proximity to the coastal border with Mozambique, where he conducted an informal trading business. As we sat together, he described to me his ambition to set up a mile-long, fine-mesh gill net by anchoring two large boats off the shores of the beach and stretching the net between them. He explained excitedly how he would leave the net in place for weeks at a time and that he could only imagine the vast numbers of fish that he would be able to catch. He clapped his hands together enthusiastically as he thought aloud about the considerable profits he would make from selling these imagined catches in the main market in Mtwara town. Admittedly, I was rather taken aback by his proposition, as I considered the vivid juxtaposition between this form of destructive fishing and the large-scale marine conservation effort that was ongoing inside the marine park's catchment area.

Curious, I asked him whether the hypothetical fear of repercussions would deter him from ever acting on his ambitious plan. To this, he replied quite simply: "It's worth the risk! I'll be rich5!" His response to this question highlights a simple consideration that cannot be overlooked: that there are significant material benefits for people to fish in destructive ways. Such potential economic gains can motivate people to openly transgress fishing gear regulations, despite the potential repercussions of doing so. As he alludes to, the possible payoffs associated with the activity often justify the risk of being caught and punished by park rangers or other governing authorities.

From an observer's standpoint, it is easy to simply attribute these material motivations to greed. Such an interpretation of this individuals' motivations, however, runs the risk of overemphasizing the psychological dimensions of his ambition, while myopically obscuring the structural factors that have influenced his way of thinking. His set of values is embedded in a neoliberal socioeconomic and political landscape that emphasizes the responsibility of individual citizens to take measures to safeguard their own security, health and well-being. Destructive fishing provides a potentially rapid route for individuals to accumulate capital that can be used to secure the basic resources that are necessary for subsistence. This individual's life had been directly shaped by poverty. As a young boy, he had dropped out of school to work on the streets of Dar es Salaam, where he would buy and sell DVDs for a miniscule profit; he would use these profits to buy milk and bread. Since then, he has continued to engage in informal business ventures and petty roadside trading in the absence of accessible formal employment opportunities. Put simply, the economic structures that have shaped the trajectory of his life have led him to consider destructive fishing as a feasible livelihood option to earn an income and escape the grips of poverty.

This individual's story elucidates the importance of situating cases of ecologically destructive practices in relation to the political and economic conditions that frame individual decision-making (see Raycraft 
2018). Disentangling the rational cost-benefit analyses of individual actors from the structural constraints on agency engendered by conditions of extreme poverty is very challenging. Often, the line between those individuals motivated by the prospect of excessive profits and those who are engaging in short-term survival strategies for basic subsistence is difficult to demarcate from the perspective of a detached observer. Given the relative lack of formal employment opportunities for uneducated people living in rural Tanzania, however, the structural economic drivers of destructive fishing cannot be overlooked. This is especially true in rural Mtwara, where poverty is particularly widespread.

Furthermore, we cannot disregard the fact that landscapes are both material and symbolic (Moore 1998). When ecologically destructive practices take place inside the boundaries of protected areas, we must consider the extent to which such acts of transgression reflect simple attempts to fulfil basic material needs or whether they constitute politically charged acts of resistance. To add further ambiguity, how do we effectively describe contexts where moral economies of subsistence blur the lines between livelihood practices and acts intended to facilitate political mobility? David Hoffman (2014) and George Holmes (2007) have effectively applied James Scott's (1985) work on everyday forms of resistance in their analyses of the reasons why people engage in both subtle forms of foot-dragging and overt forms of protest in response to conservation projects. To what extent does the visibility of these actions relate to their political undertones? Acts undertaken at night avoid direct surveillance, enabling actors to mitigate potential repercussions from governing authorities (Scott 1985). Those which occur in broad daylight could reflect more open forms of protest. When an act of dynamite fishing occurs in broad daylight, within the catchment area of a marine park, is it simply an exploitative act aimed at generating profits? Or could we consider it an overt act of protest, given its public visibility, and the meanings it holds in relation to the conservation regulations intended to restrict the practice? As Katikiro and Mahenge (2016:10) suggest, some fishers in Tanzania may "use illegal and destructive fishing methods to secure control over resources". This to me speaks to the importance of Geertzian (1973:9) attempts to differentiate the twitch-like acts, driven by basic material motivations, from the "winks upon winks upon winks" that carry layers of symbolic meaning in relation to social and political context.

\section{Multidimensionality and Multidirectionality}

This consideration serves as an important reminder of the fact that human-environment relations are inherently multidimensional (Lepofsky et al. 2017). Turner and Berkes (2006) note that there are multiple, multi-scalar pathways through which people come to understand and relate to the environment; people acquire environmental knowledge in myriad ways and environmental practices emerge over time. Without attending to inter-relational processes of learning and knowledge acquisition, ethnographic interpretation becomes even more murky.

Attempting to document the "multidimensionality" of human-environment relations in a manner that is respectful, accurate and ethically grounded is deeply challenging (Lepofsky et al. 2017:449). As an observer of dynamite fishing, I was forced to form a mental narrative with little triangulation from the perspectives of the dynamite fishers and other involved agents. In writing about such an experience, it became particularly challenging to address diverse moral terrains, especially those which remained unknown to me.

This methodological critique is not new. As Malinowski (1922:3-4) wrote almost a century ago, "in ethnography, the distance is often enormous between the brute material of information-as it is presented to the student in his own observations, in native statement, in the kaleidoscope of tribal lifeand the final authoritative presentation of the results". In my case, the "kaleidoscope" of interwoven moral terrains underlying dynamite fishing was very difficult to explicate. These were further complicated by limits on the duration of my fieldwork, my modest linguistic skills, and my background as a scuba diver.

Anthropology itself is a discipline wrought with conflict-at once seeking an object of study, while constantly adapting to shifting moral positionalities (Rabinow 2007). For ethnographers, such tensions can invoke deeply transformative self-reflexive critiques, highlighting the multidirectionality of ethnobiological scholarship. Attempts to arrive at ethnographic truths demand philosophical attention to the range of ethical possibilities associated with doing fieldwork. Perhaps the most meaningful insights gained through ethnography are the internal contradictions that arise in the mind of the ethnog- 
rapher, which complicate singular narratives and nuance explanations of causality. Contradictions, after all, are deeply embedded within our global political and economic landscape.

Upon returning home following my fieldwork, a picture that had previously felt quite clear to me became riddled with holes in my knowledge. Faced with practical questions about how property regimes and systems of tenure had changed as a result of conservation policies, I at times questioned whether I had actually grasped anything consequential at all during my fieldwork. I have since, however, come to terms with the fact that ethnographies are "bricolages," fashioned from observable vignettes and anecdotes and woven together with a scholarly precision that perhaps does not capture the empirical messiness of social life on the ground (Levi-Strauss 1962:21).

\section{Conclusion}

In thinking critically about the role of participant observation in contemporary ethnobiological scholarship, I continually return to Geertz's (1973) classic model of interpretive anthropology. Despite its shortcomings and representational challenges, participant observation provides the bridge across which ethnographers can begin to understand the internal logics of their subjects' social worlds. Certainly, our own moral codes and dispositions as ethnographers should feature into our narrative representations of ecologically destructive practices. We are, after all, humans ourselves. But while we will always be subjective to some degree in our scholarly approaches, I believe that we, as social scientists, also have an unwavering responsibility to be empirically accurate. To do so, we must attempt to understand the intentionality behind observable actions and the social, structural, and psychological forces that bear upon them. To me, the essence of the ethnographic endeavour takes orbit around the fundamental need to engage in "imaginative acts" of interpretation, as we sift through the various layers of significance that influence visible behaviours (Geertz 1973:15). Perhaps the most meaningful ethnographic analyses of dynamite fishing and other related phenomena are those that unassumingly attempt to differentiate the "winks from twitches," even when uncertainty renders this a seemingly impossible task (Geertz 1973:16).

\section{Notes}

${ }^{1}$ My use of the phrase "conservation social science" here is born out of a paper by Nathan Bennett et al. (2016) in Biological Conservation, in which the authors outline the contributions of various social science disciplines to the field of conservation.

2In an extreme case, Clifford (1986:28-30) discusses the controversy over Florinda Donner's work "Shabono," which was considered by many within the field of anthropology to be a fabrication.

${ }^{3}$ Dynamite catches in coastal Mtwara are often sold directly in the markets of Mtwara town.

${ }^{4}$ All subject names in this paper are pseudonyms.

5Juma spoke some English, acquired through his background in informal trading.

\section{Acknowledgments}

An earlier draft of this paper was presented at the conjoined 2017 International Union of Anthropological and Ethnological Sciences (IUAES)/ Canadian Anthropology Society (CASCA) meetings in Ottawa, Canada. I am grateful to the panel participants for their feedback. I would also like to thank Steve Wolverton, whose constructive comments on the piece helped to provide analytical texture, and Elizabeth Olson for her editorial help in shepherding this piece towards publication. I owe special thanks to Vinay Kamat for his tireless support as a graduate supervisor, especially while I was conducting fieldwork.

\section{Declarations}

Permissions: Ethics approval for fieldwork was issued by The UBC Behavioural Research Ethics Board (approval number H14-01713). The permit to conduct research in Tanzania was issued by The Tanzania Commission for Science and Technology (COSTECH) (research permit number 2013-240-ER2008-68).

Sources of Funding: Fieldwork was supported by a Joseph Armand Bombardier Scholarship (CGS-M) from the Social Sciences and Humanities Research Council of Canada. The author was supported by a Vanier Canada Graduate Scholarship while preparing this article.

Conflicts of Interest: None declared. 


\section{References Cited}

Bennett, N. J., R. Roth, S. C. Klain, K. Chan, P. Christie, D. A. Clark, G. Cullman, D. Curran, T. J. Durbin, G. Epstein, A. Greenberg, M. P. Nelson, J. Sandlos, R. Stedman, T. L. Teel, R. Thomas, D. Verissimo, and C. Wyborn. 2017. Conservation Social Science: Understanding and Integrating Human Dimensions to Improve Conservation. Biological Conservation 205:93-108. DOI:10.1016/ j.biocon.2016.10.006.

Blaike, P. 1989. Environment and Access to Resources in Africa. Africa: Journal of the International African Institute 59:18-40. DOI:10.2307/1160761.

Boelens, R., J. Hoogesteger, E. Swyngedouw, J. Vos, and P. Wester. 2016. Hydrosocial Territories: A Political Ecology Perspective. Water International 41:1-14. DOI:10.1080/02508060.2016.1134898.

Bubandt, N., and A. Tsing. 2018. Feral Dynamics of Post-Industrial Ruin: An Introduction. Journal of Ethnobiology 38:1-7. DOI:10.2993/0278-077138.1.001.

Clifford, J., and G. E. Marcus, eds. 1986. Writing Culture: The Poetics and Politics of Ethnography. University of California Press, Berkeley, CA.

Darwall, W. R. T., and M. Guard. 2000. Southern Tanzania. In Coral Reefs of the Indian Ocean: Their Ecology and Conservation, edited by T. R. McClanahan, C. R. C. Sheppard, and D. O. Obura, pp. 131 -167. Oxford University Press, New York.

Escobar, A. 1999. After Nature: Steps to an Antiessentialist Political Ecology. Current Anthropology 40:1-30. DOI:10.1086/515799.

Fairhead, J., and M. Leach. 1995. False Forest History, Complicit Social Analysis: Rethinking some West African Environmental Narratives. World Development 23:1023-1035. DOI:10.1016/0305-750X(95)00026-9.

Favret-Saada, J. 2012. Being Affected. HAU: Journal of Ethnographic Theory 2:435-445. DOI:10.14318/ hau2.1.019.

Figueroa, R. M., and G. Waitt. 2008. Cracks in the Mirror: (Un) covering the Moral Terrains of Environmental Justice at Uluru-Kata Tjuta National Park. Ethics Place and Environment 11:327349. DOI:10.1080/13668790802559726.

Figueroa, R. M., and G. Waitt. 2010. Climb: Restorative Justice, Environmental Heritage, and the Moral Terrains of Uluru-Kata Tjuta National Park.
Environmental Philosophy 11:327-349. DOI:10.5840/ envirophil20107219.

Gan, E., D. Sullivan, and A. Tsing. 2018. Using Natural History in the Study of Industrial Ruins. Journal of Ethnobiology 38:39-54. DOI:10.2993/0278 -0771-38.1.039.

Gavin, M. C., J. McCarter, A. Mead, F. Berkes, J. R. Stepp, D. Peterson, and R. Tang. 2015. Defining Biocultural Approaches to Conservation. Trends in Ecology \& Evolution 30:140-145. DOI:10.1016/ j.tree.2014.12.005.

Geertz, C. 1973. The Interpretation of Cultures: Selected Essays by Clifford Geertz. Basic Books, New York.

Ghosh, A. 2016. The Great Derangement: Climate Change and the Unthinkable. University of Chicago Press, Chicago.

Gilmore, M. P., and J. C. Young. 2012. The Use of Participatory Mapping in Ethnobiological Research, Biocultural Conservation, and Community Empowerment: A Case Study from the Peruvian Amazon. Journal of Ethnobiology 32:6-29. DOI:10.2993/0278-0771-32.1.6.

Gilmore, M. P., and W. H. Eshbaugh. 2011. From Researcher to Partner: Ethical Challenges and Issues Facing the Ethnobiological Researcher. In Ethnobiology, edited by E. N. Anderson, D. M. Pearsall, E. S. Hunn, and N. J. Turner, pp. 51-63. Wiley-Blackwell, Hoboken, NJ. DOI:10.1002/9781118015872.ch4.

Guard, M., and M. Masaiganah. 1997. Dynamite Fishing in Southern Tanzania, Geographical Variation, Intensity of Use and Possible Solutions. Marine Pollution Bulletin 34:758-762. DOI:10.1016/ s0025-326x(98)00017-4.

Haraway, D. 2016. Staying with the Trouble: Making Kin in the Chthulucene. Duke University Press, Durham, NC. DOI:10.1215/9780822373780.

Hardison, P., and K. Bannister. 2011. Ethics in Ethnobiology: History. International Law and Policy, and Contemporary Issues. In Ethnobiology, edited by E. N. Anderson, D. M. Pearsall, E. S. Hunn, and N. J. Turner, pp. 27-49. WileyBlackwell, Hoboken, NJ. DOI:10.1002/9781118015872.ch3

Hoffman, D. 2014. Conch, Cooperatives, and Conflict: Conservation and Resistance in the Banco Chinchorro Biosphere Reserve. Conservation 
and Society 12:120-132. DOI:10.4103/09724923.138408 .

Holmes, G. 2007. Protection, Politics and Protest: Understanding Resistance to Conservation. Conservation and Society 5:184-201.

Hunn, E. 2014. To Know Them is to Love Them. Ethnobiology Letters 5:146-150. DOI:10.14237/ ebl.5.2014.297.

Kalangahe, B., and L. Slade. 2014. Multi-stakeholder Consultation for Anti-Dynamite Fishing Campaign Tanzania. Report by Mwambao Coastal Community Network. Available at: http:// cmsdata.iucn.org/downloads/

draft_report_mccn_multi_stakeholder_consulta tion_for_anti_dynamite_fishing_campaign.pdf. Accessed on September 15, 2017.

Kamat, V. 2014. The Ocean is our Farm: Marine Conservation, Food Insecurity, and Social Suffering in Southeastern Tanzania. Human Organization 73:289-298. DOI:10.17730/ humo.73.3.f43k115544761g0v.

Katikiro, R. E., and J. J. Mahenge. 2016. Fishers' Perceptions of the Recurrence of DynamiteFishing Practices on the Coast of Tanzania. Frontiers in Marine Science 233:1-14. DOI:10.3389/ fmars.2016.00233.

Kohn, E. 2013. How Forests Think: Towards an Anthropology Beyond the Human. University of California Press, Berkeley, CA. DOI:10.1525/ California/9780520276109.003.0004.

Latour, B. 2004. Politics of Nature: How to Bring the Sciences into Democracy. Harvard University Press, Cambridge, MA.

Lepofsky, D., C. G. Armstrong, S. Greening, J. Jackley, J. Carpenter, B. Guernsey, D. Mathews, and N. J. Turner. 2017. Historical Ecology of Cultural Keystone Places of the Northwest Coast. American Anthropologist 119:448-463. DOI:10.1111/aman.12893.

Levi-Strauss, C. 1962. The Savage Mind. G. Weidenfield, trans. University of Chicago Press, Chicago.

Malinowski, B. 1922. Argonauts of the Western Pacific. Routledge and Kegan Paul, London.

Marcus, G., and M. M. J. Fischer. 1986. Anthropology as Cultural Critique: An Experimental Moment in the Human Sciences. University of Chicago Press, Chicago.
Moore, D. S. 1998. Clear Waters and Muddied Histories: Environmental History and the Politics of Community in Zimbabwe's Eastern Highlands. Journal of Southern African Studies 24:377-403. DOI:10.1080/03057079808708581.

Nabhan, G. P. 2009. Perspectives in Ethnobiology: Bridging Disciplines, Cultures and Species. Journal of Ethnobiology 29:3-7. DOI:10.2993/0278-077129.1.3.

Nabhan, G. P., F. Wyndham, and D. Lepofsky. 2011. Ethnobiology for a Diverse World: Ethnobiology Emerging from a Time of Crisis. Journal of Ethnobiology 31:172-175. DOI:10.2993/0278-077131.2.172.

Rabinow, P. 2007. Reflections on Fieldwork in Morocco. University of California Press, Oakland, CA.

Raffles, H. 1999. "Local Theory": Nature and the Making of an Amazonian Place. Cultural Anthropology 14:323-360. DOI:10.1525/can.1999.14.3.323.

Raycraft, J. 2018. Marine Protected Areas and Spatial Fetishism: A Viewpoint on Destructive Fishing in Coastal Tanzania. Marine Pollution Bulletin 133:478480. DOI:10.1016/j.marpolbul.2018.06.008.

Ryle, G. 1971. Collected Papers. Volume II: Collected Essays 1929-1968. Hutchison, London.

Saslis-Lagoudakis, C. H., and A. C. Clarke. 2013. Ethnobiology: The Missing Link in Ecology and Evolution. Trends in Ecology \& Evolution 28:67-68. DOI:10.1016/j.tree.2012.10.017.

Scott, J. 1985. Weapons of the Weak: Everyday Forms of Peasant Resistance. Yale University Press, New Haven, CT.

Tsing, A. L. 2015. The Mushroom at the End of the World: On the Possibility of Life in Capitalist Ruins. Princeton University Press, Princeton, NJ.

Turner, N. J., and F. Berkes. 2006. Coming to Understanding: Developing Conservation Through Incremental Learning in the Pacific Northwest. Human Ecology 34:495-513. DOI:10.1007/s10745006-9042-0.

Viveiros de Castro, E. 1998. Cosmological Deixis and Amerindian Perspectivism. The Journal of the Royal Anthropological Institute 4:469-488. DOI:10.2307/3034157.

Waitt, G., R. Figueroa, and L. McGee. 2007. Fissures in the Rock: Rethinking Pride and Shame in the Moral Terrains of Uluru. Transactions of the Institute 
of British Geographers 32:248-263. DOI:10.1111/ j.1475-5661.2007.00240.x.

Walley, C. J. 2004. Rough Waters: Nature and Development in an East African Marine Park. Princeton University Press, Princeton, NJ.

Wells, S. 2009. Dynamite Fishing in Northern Tanzania - Pervasive, Problematic and yet Preventable. Marine Pollution Bulletin 58:20-23. DOI:10.1016/j.marpolbul.2008.09.019.

Wolverton, S. 2013. Ethnobiology 5: Interdisciplinarity in an Era of Rapid Environmental Change. Ethnobiology Letters 4:21-25. DOI:10.14237/ ebl.4.2013.11.

Wolverton, D., R. M. Figueroa, and P. Swentzell. 2016. Archaeology, Heritage, and Moral Terrains: Two Cases from the Mesa Verde Region. Ethnobiology Letters 7:23-31. DOI:10.14237/ ebl.7.2.2016.695.
Wolverton, S., J. M. Nolan, and W. Ahmed. 2014. Ethnobiology, Political Ecology, and Conservation. Journal of Ethnobiology 34:125-152. DOI:10.2993/0278-0771-34.2.125.

Wyndham, F. S. 2009. Spheres of Relations, Lines of Interaction: Subtle Ecologies of the Raramuri Landscape in Northern Mexico. Journal of Ethnobiology 29:271-295. DOI:10.2993/0278-0771-29.2.271.

Wyndham, F. S., D. Lepofsky, and S. Tiffany. 2011. Taking Stock in Ethnobiology: Where Do We Come From? What Are We? Where Are We Going? Journal of Ethnobiology 31:110-127. DOI:10.2993/0278-0771-31.1.110. 